\title{
O trabalho na gestão dos serviços substitutivos de saúde mental: aproximações entre Saúde Coletiva, Saúde Mental e Psicanálise
}

\section{| ${ }^{1}$ Rosângela Machado Moreira, ${ }^{2}$ Katia Bones Rocha |}

Resumo: Objetiva-se investigar as inter-relaçóes entre os campos da Saúde Coletiva, da Saúde Mental e da Psicanálise, na gestão de serviços de saúde mental, no contexto do Sistema Único de Saúde. Trata-se de pesquisa qualitativa realizada em quatro municípios do estado do Rio Grande do Sul, Brasil, com seis gestoras de serviços de saúde mental identificadas com a psicanálise. Os instrumentos de coleta de dados empregados foram uma ficha de dados pessoais e sociodemográficos e uma entrevista semiestruturada. Utilizou-se a análise temática para o exame dos dados, resultando na identificação de três temas centrais: 1) Formação e experiência em gestão e em Saúde Coletiva; 2) Lógica manicomial versus lógica reformista: desafios para o gestionar; e 3) Psicanálise: entre contribuiçóes e limites. Os resultados apontam as dificuldades e os desafios para o gestionar diante da coexistência, nos serviços, de diferentes lógicas de cuidado em saúde mental. A Psicanálise é assumida como um posicionamento ético-político a partir da escuta dos processos inconscientes dos sujeitos, os quais se dão no campo transferencial, contribuindo no suporte à compreensão dos casos e no manejo dos aspectos relacionais e institucionais. Por outro lado, há a necessidade de aproximação da psicanálise com o contexto da saúde mental.

> Palavras-chave: reforma psiquiátrica; psicanálise; gestão em saúde; serviços de saúde mental.

\author{
1 Departamento de Ações em \\ Saúde, Secretaria Estadual \\ de Saúde do Rio Grande do \\ Sul. Porto Alegre-RS, Brasil \\ (romoreirapsico@gmail.com). \\ ORCID: 0000-0002-6694-4528 \\ 2 Pós-Graduação em Psicologia, \\ Pontifícia Universidade \\ Católica do Rio Grande do \\ Sul. Porto Alegre-RS, Brasil \\ (katiabonesrocha@gmail.com). \\ ORCID: 0000-0001-7603-1709.
}

Recebido em: 17/02/2019 Revisado em: 31/03/2019 Aprovado em: 08/04/2019 


\section{Introdução}

A Saúde Coletiva caracteriza-se por um processo de "movimento pendular", tendo como referência os movimentos que atravessam a saúde como um todo (L'ABBATE, 2003). Busca-se, dessa forma, estabelecer relaçóes dialéticas, de antagonismos e de complementaridade entre os distintos modos de se produzir saúde, isto é, entre objetividade e subjetividade, especialização e trabalho multiprofissional, conhecimento e prática. Sob essa ótica, a psicanálise, na sua aplicação a grupos e instituiçôes, tem uma importante contribuição à Saúde Coletiva, como teoria que a pense como uma construção sócio-histórica de sujeitos, pois se caracteriza como "um método consciente (racional e deliberado) para se lidar com o inconsciente e a incoerência constitutivos de todo e qualquer sujeito" (CAMPOS, 2000, p. 224).

A interseção entre a Psicanálise, a Saúde Coletiva e a Saúde Mental é histórica e condizente com o surgimento de novas práticas em saúde mental. Essa aproximação está atrelada ao processo de Reformas Sanitária e Psiquiátrica no Brasil, que inaugurou um novo olhar para o sujeito em sofrimento psíquico a partir da escuta e do respeito a sua história e singularidade (TENÓRIO, 2002).

Para a substituição do modelo hospitalocêntrico e efetiva implementação da Reforma Psiquiátrica brasileira, foi criada uma rede de serviços substitutivos em saúde mental, entre eles os Centros de Atenção Psicossocial (CAPS) e os Núcleos de Apoio à Saúde da Família (NASF) (BRASIL, 2011). Os serviços substitutivos possuem a potência de se constituírem como espaços que efetivamente permitem ao sujeito em sofrimento psíquico ter uma rede de cuidados no território e viver em comunidade. Ao mesmo tempo, a gestão desses espaços é marcada por tensôes e conflitos nos modos de cuidado, pautados, por um lado, pelo modelo tradicional biomédico, de compreender os processos saúde/doença e atenção e, por outro, por propostas que trazem em seu bojo os ideais das Reformas Sanitária e Psiquiátrica (LEITE; SCARPARO; OLIVEIRA, 2013; NUNES; GUIMARÁES; SAMPAIO, 2016).

Entre as funções exercidas pela gestão nos serviços de saúde, está a de criar espaços de circulaçấo da palavra e intercâmbios autorreflexivos que possibilitam a democratização e um maior grau de análise sobre as práticas (CAMPOS, 2015). No sentido psicanalítico, contudo, há a necessidade de compreensão de que esses espaços são frequentemente lugar de encenação de processos inconscientes, os quais operam através da relação entre os sujeitos (ONOCKO-CAMPOS, 2005; 2012). Assim, a 
gestâo pode contribuir dando certa regularidade aos espaços grupais, exercendo a função de suporte e manejo do grupo, ao mesmo tempo que auxilia na constituição de uma grupalidade operativa, isto é, em que os trabalhadores possam se implicar e explorar sua autonomia e criatividade (ONOCKO-CAMPOS, 2007).

Diversos estudos apontam a importância do papel da gestáo na determinação do funcionamento dos serviços de saúde pautado pelas diretrizes e prerrogativas do Sistema Único de Saúde (SUS), na organização e no planejamento das ações e na forma como se operacionalizam os processos de trabalho (NUNES et al., 2016; OHIRA; CORDONI JUNIOR; NUNES, 2014a; SULTI et al., 2015). Outras investigações assinalam as discussōes e indicaçōes de algumas especificidades do papel da gestão nos serviços substitutivos de saúde mental, tais como: representação, funçôes administrativas, manejo das relaçôes, organização do serviço e necessidade de conhecimentos de gestão, da legislação em saúde mental e do movimento da Reforma Psiquiátrica (MAYORGA; DINIZ; MONTEIRO, 2009; SILVA; CAMPOS, 2015).

Tendo em vista a relevância do papel desempenhado pela gestão no cotidiano dos serviços de saúde mental e no modo como se efetivam o trabalho e o cuidado, observa-se a necessidade de investigações que se debrucem sobre essa prática, pois ela é pouco pesquisada empiricamente. A partir da interseçâo com o campo da Psicanálise, objetiva-se delinear as contribuiçôes à gestão dos aportes teóricos e técnicos próprios desse campo de saber. Sendo assim, a presente pesquisa teve como propósito investigar as inter-relaçóes entre os campos da Saúde Coletiva, da Saúde Mental e da Psicanálise na gestão de serviços de saúde mental, no âmbito do SUS.

\section{Método}

Optou-se por um método qualitativo de caráter exploratório, tendo em vista os objetivos deste estudo. Segundo Minayo (2010), o método qualitativo, através da análise dos achados, proporciona a ampliação do conhecimento sobre o significado dos eventos e sua repercussão sobre a subjetividade.

A pesquisa foi realizada em Porto Alegre, capital do estado do Rio Grande do Sul, e em três municípios da sua região metropolitana. A escolha dos participantes se deu a partir de uma rede de conveniência, bem como pela técnica "bola de neve" (TURATO, 2003), na qual um participante indica outros e assim por diante. Como 
critério de inclusão, todos os profissionais deveriam ter formação, especialização ou outra forma de aquisiçáo teórica ou teórico-prática em psicanálise e com um período mínimo de seis meses de prática na gestão de serviços de saúde mental, no contexto do SUS, mais especificamente nos Núcleos de Apoio à Saúde da Família (NASF) e nos Centros de Atenção Psicossocial (CAPS). Para a determinação do número de sujeitos, empregou-se o critério de saturação teórica (FLICK, 2009).

Os instrumentos utilizados para a coleta de dados foram: uma ficha de dados pessoais e sociodemográficos, a qual buscou caracterizar os participantes do estudo, e uma entrevista semiestruturada, que, a partir de um roteiro previamente elaborado, possibilitou aos entrevistados exporem suas consideraçóes sobre o tema proposto (MINAYO, 2010). O roteiro da entrevista semiestruturada foi composto pelos seguintes eixos temáticos: a) formação/capacitação técnica específica para a atuação na gestão; b) especificidade do trabalho na gestão de serviços de saúde mental; c) utilização de dispositivos de gestão participativa e cogestão propostos pelo SUS; e d) interfaces com a psicanálise. As entrevistas, num total de seis, foram realizadas entre os meses de abril e junho de 2018.

Depois de gravadas e transcritas, as entrevistas foram examinadas por meio da análise temática, proposta por Braun e Clarke (2006), com o auxílio do software ATLAS Ti, Versão 1.0.36 (MUHR, 2013). A análise temática é um método para identificar, examinar e relatar padróes (temas) dentro dos dados, organizando e descrevendo o conjunto de informaçóes em detalhes, podendo ir além, interpretando os vários aspectos do tema de pesquisa (BOYATZIS, 1998). Nesta etapa, tal como propóem Braun e Clarke (2006), buscou-se primeiramente a familiarização com os dados, através da leitura flutuante de cada uma das entrevistas; após, realizou-se uma nova leitura do material, estabelecendo-se a geração de códigos iniciais; em seguida, esses foram agrupados em subtemas; e por fim, em temas centrais. Os dados foram analisados a partir de três campos de saberes e práticas: Saúde Coletiva, Saúde Mental e Psicanálise.

Quanto aos aspectos éticos, o estudo foi norteado pelos princípios abrangidos na Resolução no 510/2016, do Conselho Nacional de Saúde (BRASIL, 2016). O projeto foi aprovado pelo Comitê de Ética em Pesquisa, sob o número 2.561.827/2018. A fim de garantir o anonimato dos participantes, as falas foram identificadas pela letra E, seguida por um algarismo de acordo com a ordem das entrevistas (E1, E2...). 


\section{Resultados e Discussão}

Todas as entrevistadas deste estudo são do sexo feminino, com idade média de 39 anos. No que diz respeito à experiência no campo da saúde mental, uma atua há menos de cinco anos, duas, de cinco a dez anos, e três, um tempo superior a dez anos. Com relação ao tempo no cargo de gestão, cinco estão há mais de três anos. No que tange à escolaridade, verificou-se que todas as gestoras possuem ensino superior completo, sendo que cinco são psicólogas e uma terapeuta ocupacional. Quanto à pós-graduação, cinco delas têm residência multiprofissional em saúde coletiva.

Como resultado do processo de codificaçáo das entrevistas, foram identificados dez códigos iniciais, os quais foram agrupados em seis subtemas e, por fim, em três temas centrais. $\mathrm{O}$ quadro 1 objetiva apresentar didaticamente a construção dos mesmos.

Quadro 1. Categorias de análise construídas a partir da percepção das entrevistadas. Rio Grande do Sul, 2018

\begin{tabular}{|c|c|c|}
\hline Códigos iniciais & Subtemas & Temas centrais \\
\hline $\begin{array}{l}\text { - Ausência de formação específica } \\
\text { para atuar na gestão; } \\
\text { • Importância de uma } \\
\text { especializaçãa/formação em } \\
\text { saúde pública; e } \\
\text { • Formação da coordenação: } \\
\text { influência na forma como são } \\
\text { conduzidos os processos. }\end{array}$ & $\begin{array}{l}\text { - Ausência de formação } \\
\text { específica para a atuação } \\
\text { na gestão; e } \\
\text { - Importância de } \\
\text { formação/experiência } \\
\text { em Saúde Coletiva. }\end{array}$ & $\begin{array}{l}\text { - Formação e experiência } \\
\text { em gestão e em Saúde } \\
\text { Coletiva }\end{array}$ \\
\hline $\begin{array}{l}\text { - Importância de toda a equipe } \\
\text { estar sustentada pela mesma } \\
\text { lógica de saúde mental; } \\
\text { - Conflitos entre a lógica } \\
\text { reformista e a lógica } \\
\text { manicomial; e } \\
\text { - Dificuldade/importância de } \\
\text { constituir/manter espaços de } \\
\text { gestáo participativa e controle } \\
\text { social. }\end{array}$ & $\begin{array}{l}\text { - Conflitos entre a lógica } \\
\text { reformista e a lógica } \\
\text { manicomial; e } \\
\text { - Importância de toda a } \\
\text { equipe estar sustentada } \\
\text { pela mesma lógica de } \\
\text { saúde mental. }\end{array}$ & $\begin{array}{l}\text { - Lógica manicomial } \\
\text { versus lógica reformista }\end{array}$ \\
\hline
\end{tabular}

continua... 


\begin{tabular}{|l|l|l|}
\hline Códigos iniciais & Subtemas & Temas centrais \\
\hline • Psicanálise: auxílio quanto aos & • Posicionamento ético- & \\
aspectos subjetivos dos sujeitos & político da psicanálise: & \\
e do grupo; & escuta dos processos & \\
• Necessidade de uma psicanálise & inconscientes que se dão & \\
que se aproxime da saúde & no campo transferencial; & • Psicanálise: entre \\
mental coletiva; & e contribuiçóes e limites \\
- Importância de toda a equipe & • Necessidade de uma & \\
ter uma identificação com a & psicanálise que se & \\
psicanálise; e & aproxime da saúde & \\
• Psicanálise como um & mental coletiva. & \\
posicionamento ético-político. & & \\
\hline
\end{tabular}

Fonte: Autoria própria.

\section{Formação e experiência em gestão e em Saúde Coletiva}

Neste estudo, todas as entrevistadas referiram não ter formação específica para atuar como gestoras. Tal achado corrobora outros estudos, que ressaltam a ausência dessa formação entre os gestores de serviços de saúde entrevistados e destacam os prejuízos para o planejamento e gestão do serviço (NUNES et al., 2016; OHIRA; CORDONI JUNIOR; NUNES, 2014a, 2014b). "Pois eu não tive nenhuma formação específica em gestão [...]”. (E6)

Eu nunca tinha trabalhado na gestão [...] com um conhecimento realmente mais técnico [...], mas faltando muito essa questão da gestão. [...] mas eu acho que, nossa, o prejuízo é muito de um fazer que fica ilhado quando tu não tem uma preparação. (E2)

Por outro lado, ainda que não tenham tido formação específica na área da gestão, a maioria das entrevistadas afirma que a experiência na área da Saúde Coletiva, por meio da residência multiprofissional, possibilitou a qualificação de sua atuação como gestora, através das vivências no dia a dia dos serviços. Além disso, as atividades teórico-práticas contribuíram para a ampliação do olhar sobre os aspectos que envolvem o fazer na gestão, com ênfase no compartilhamento das decisões.

[...] a residência é muito importante para pensar e atuar de uma forma de corresponsabilização assim entre equipe. De pensar também na gestão que vai para além da equipe, porque é superdifícil, que é pensar no usuário junto nessa gestão [...]. Acho que minha formação começou muito... pela Residência. De que eu também fazia parte dessa gestão, dessa coordenação do serviço. E de pensar de forma compartilhada. (E5) 
As contribuiçôes das experiências em Saúde Coletiva através da Residência, ressaltadas pelas entrevistas, vão ao encontro da afirmaçáo feita por Feuerwerker (2009) de que a especialização pelo trabalho pode ser um espaço de invenção para a ampliação da escuta, para a produção de novas tecnologias de cuidado e ampliação da construção compartilhada de projetos terapêuticos, com a participação do usuário. Corroborando, Campos (2015) postula que a gestão deve conhecer em profundidade o campo de saberes e práticas no qual a instituição se insere, tais como a atenção à saúde, métodos pedagógicos, entre outros, mais do que conhecimentos específicos de economia ou administração, sendo prioritária a experiência prévia no campo de atuação.

Estudos demonstram a característica de inovação, mobilização e transformação da residência multiprofissional em saúde para todos os atores envolvidos no processo, sejam residentes, trabalhadores, preceptores, gestores ou usuários (CASANOVA; BATISTA; RUIZ-MORENO, 2015; DOMINGOS; NUNES; CARVALHO, 2015; GADELHA; BARRETO, 2018; NORDI; ACIOLE, 2017). Por meio da residência, é possível promover mudanças no curto prazo, a partir da busca de solução de problemas no próprio território; em médio prazo, por meio da implantação de atividades de promoção de saúde e qualidade e de vida; e no longo prazo, ao possibilitar o conhecimento da comunidade sobre seu processo de saúdedoença (GADELHA; BARRETO, 2018).

\section{Lógica Manicomial versus Lógica Reformista: desafios para a gestáo}

Os equipamentos substitutivos em saúde mental por vezes sofrem o risco de "manicomialização" e deslegitimização social (ONOCKO-CAMPOS; FURTADO, 2006), através de discussôes científicas e produção do conhecimento com ênfase em temas farmacológicos e diagnósticos, em detrimento dos que vinculem saúde mental, contexto social e saúde pública (BRASIL, 2002). Da mesma forma, práticas de cuidado fragmentadas, a não articulação em rede, a centralização na medicalização, a ausência de processos democráticos de trabalho e de participação e controle social são açôes que aproximam os novos equipamentos do modelo manicomial (AMARANTE; TORRE, 2001; SILVA; CAMPOS, 2015). 
Nas entrevistas realizadas, todas as gestoras enfatizam as dificuldades e os desafios do trabalho na gestão diante da coexistência, por um lado, da lógica manicomial de cuidado em saúde mental, pautada pelo viés biomédico, e, por outro, da lógica reformista, de desinstitucionalização da loucura e do louco. A lógica manicomial perpassa e dificulta a atuação na gestão a partir de diversos pontos: a) na forma como a equipe escuta e intervém junto aos usuários e familiares; b) no modo de cuidado solicitado por estes; c) no modelo de cuidado que orienta a atuação dos outros serviços da Rede de Atenção Psicossocial; d) na maneira como são propostas, implementadas e modificadas as políticas públicas pela gestão municipal e federal; e e) na dificuldade para a constituição e manutenção de espaços de gestão participativa e controle social. Esses diversos movimentos, orientados pela lógica manicomial, exigem das entrevistadas, enquanto gestoras dos serviços que atuam, um fazer marcado por conflitos, tensionamentos e açóes de resistência, que recoloquem a lógica reformista em primeiro plano.

Eu acho que o maior desafio [...] é lidar com o público infanto-juvenil em um serviço de saúde mental no momento que a gente vive, [...] de uma medicalizaçáo da infância que se coloca o tempo inteiro. Eu acho que o maior desafio é a gente poder sustentar junto com o familiar, junto com a equipe, junto com o usuário, que ele náo precisa de um... Que ele não vai ter um diagnóstico fechado com três anos de idade, de que ele pode sim ser cuidado com outras formas que não só a consulta com a psiquiatra... com o grupo, com a interação, com outras experiências. (E2)

[...] quando a gente entra nas unidades, a gente sempre vai tentando discutir e mostrar para a equipe uma outra lógica de cuidado, uma outra lógica de trabalho inclusive, mas quando a gente vê que, ainda assim, não é possível se avançar, a gente, entấo, conversa com a gestão, com a gestão da atenção básica, no caso, alguém responsável na gestáo por aquelas unidades para a gente tentar alinhar um trabalho que possa ser efetivo [...]. (E3)

Quanto aos movimentos guiados pela lógica manicomial no âmbito da gestáo federal, as entrevistadas destacam as diversas mudanças e retrocessos que vêm ocorrendo no SUS e na política de saúde mental, os quais impactam nas lógicas de cuidado do dia a dia dos serviços e que, portanto, influenciam e dificultam o seu trabalho como gestoras. Uma das mudanças ressaltadas pelas entrevistadas é concernente à Política Nacional de Atenção Básica (PNAB) 2017 (BRASIL, 2017a).

[...] e isso caiu por terra a obrigatoriedade de ter Agente de Saúde compondo a equipe [...]. Porque a questão do território, a questão dos agentes comunitários, eles são fundamentais para se pensar no processo de saúde mental das pessoas, já trazendo toda a questão do que veio com a Reforma Psiquiátrica, de outras terapêuticas [...]. (E3) 
Conforme Morosini, Fonseca e Lima (2018), as mudanças na nova PNAB representam retrocessos e riscos, pois reforçam a subtração de direitos e o movimento de desconstrução do SUS em curso no Brasil. Segundo as autoras, entre as modificaçôes presentes na nova PNAB, estão: a) a relativização da cobertura; b) o reposicionamento da Estratégia Saúde da Família e a retomada da Atenção Básica tradicional, por meio da não exigência da presença dos agentes comunitários de saúde na composição mínima das equipes de Atenção Básica; e c) a fusão dos agentes comunitários de saúde e dos agentes de combate às endemias, havendo uma descaracterização de seu trabalho, que já vêm se afastando das ações de educação em saúde.

Também são assinaladas pelas entrevistadas as dificuldades relacionadas às mudanças na política de saúde mental, através da Resolução no 32 (BRASIL, 2017b). As alteraçôes contidas nesta norma jurídica rompem com a lógica de desestruturação de manicômios ao incluir os hospitais psiquiátricos especializados (art. 1º) no rol de componentes da Rede de Atenção Psicossocial (RAPS). Além disso, há a proposição de ampliação, qualificação e expansão dos leitos hospitalares psiquiátricos (art. 9o), fato que vai de encontro à proposta da reforma psiquiátrica antimanicomial de progressiva extinção desses leitos. Por fim, destaca-se, entre outras mudanças, o evidente interesse em incluir as comunidades terapêuticas na RAPS, por meio do fortalecimento da parceria e do apoio intersetorial entre os diferentes ministérios em relação a elas $\left(\right.$ art. $\left.11^{\circ}\right)$.

[...] a gente tem visto acontecer agora recentemente de investir muito mais dinheiro em comunidades terapêuticas, por exemplo, do que em CAPS. Que cuidado é esse que a gente está falando? (E3).

Eu acho que é um cenário da saúde mental que está se desenhando, assim, de um retrocesso [...] a sensação que dá é que a gente está recomeçando de novo a ter que ser mais claro sobre coisas que já estavam dadas. Pareciam que já estavam dadas. Na verdade, nunca estiveram dadas [...]. (E2)

A política de saúde mental até então vigente, apoiada na hegemonia reformista, integrava um sistema de serviços de saúde em construção, "ainda inacabado, incompleto, com problemas a serem resolvidos e desafios a serem enfrentados para a concretização dos seus princípios e diretrizes" (TEIXEIRA, 2004, p. 13). Por outro lado, vinha conquistando avanços efetivos através da implementação, expansão e consolidação da rede de serviços substitutivos de saúde mental (BARROS; SALLES, 2011). Sendo assim, era possível o cuidado das pessoas em sofrimento psíquico grave 
junto à sociedade, contribuindo, desta forma, para novos olhares sobre a loucura, menos estigmatizantes e segregadores.

A saúde mental, como campo característico de disputas, confrontos e lutas, se coloca, entâo, como um espaço que pode possibilitar o destacamento de práticas calcadas na lógica antirreforma psiquiátrica; contudo, também pode permitir a emergência de movimentos de resistência, de linhas de fuga. Esses podem se dar tanto a partir da micropolítica, exercida por cada ator social a partir do trabalho vivo em ato (MERHY, 2002), quanto através de processos macropolíticos, tais como os movimentos sociais, que incidam nas instâncias de decisão responsáveis pela implantação e implementação das políticas públicas.

Nesse sentido, um dos pontos salientados pelas gestoras como apoiadores e fortalecedores do seu fazer diz respeito à imprescindibilidade que a lógica reformista oriente o trabalho de toda a equipe que atua nos serviços de saúde mental. Essa característica, diante dos diversos movimentos antirreforma que vinham na esteira da hegemonia reformista e que agora se mostram intensificados a partir da conjuntura macropolítica, dá sustentação à gestão e fortalece os movimentos de resistência, pois se dá por meio do coletivo.

Essa é para mim a maior semelhança, que me aproxima deles, é na discussão de caso a gente poder [...] tentar conduzir o caso da forma que o usuário possa viver em liberdade, não ao contrário. Acho que quando chega alguém muito numa visão manicomial dentro da equipe, quebra, sabe, dificulta o trabalho. (E1)

E a gente resiste todo dia. Acho que dentro dos grupos, dentro do serviço... acho que é uma equipe muito boa assim, que ajuda muito nisso. Acho que eu consigo resistir para isso que está acontecendo é tu saber que tem uma equipe que náo vai decidir por [...] esse paradigma assim, mais biomédico e mais de internação. (E5)

Frente a um cenário de retrocessos e precarização das políticas, destacam-se os movimentos que ocorrem pelo conjunto dos atores que compóem os serviços de saúde mental. As estratégias de resistência pela via do coletivo possuem o potencial, a partir da conjugação do singular e do comum, de efetivamente promoverem mudanças e novas formas de expressão e de vida (MONTEIRO; COIMBRA; MENDONÇA FILHO, 2006).

\section{Psicanálise: entre contribuiçôes e limites}

Nas entrevistas realizadas, as gestoras assinalam as interseçôes entre a Psicanálise e a Saúde Mental, no que concerne às possibilidades e aos limites desse encontro. 
Por meio de uma gestão alicerçada nos processos subjetivos e intersubjetivos que perpassam as instituiçôes, a Psicanálise é assumida como um posicionamento éticopolítico a partir da escuta dos processos inconscientes dos sujeitos, os quais se dão no campo transferencial. Munida desse referencial, a gestão subsidia a equipe na compreensão e intervenção junto aos usuários, a partir de um posicionamento calcado na escuta e no respeito à singularidade.

Mas digamos que eu acho que isso é exercido na equipe, para mim isso é importante assim, de que lugar tu fala [...], a gente sabe que coisas acontecem nesse campo transferencial. Entáo acho que é muito caro para mim tu deixar o outro falar, tu escutar de uma forma que não seja rapidamente interpretado. Acho que essa é uma contribuição da psicanálise, deixar que as coisas fluam. (E4)

O que me ocorre muito, principalmente nesse técnico que eu citei, é, por exemplo, o trabalho com autistas. A gente recebe algumas crianças com esse diagnóstico e ele tem o caso de uma menina que chegou no serviço só chorando. Ela chorava o tempo inteiro e se embalava o tempo inteiro. [...] Aí, esse técnico entra com o violão, com o recurso da música e ele vai trazendo, assim, uma outra fala, que eu digo. Ele vai usando a música e vai incluindo a menina nesse simbólico que até entâo estava muito distante. Ele vai colocando a música para que esse embalo dela acabe virando uma dança, aí o discurso dele vai nesse sentido: "Ah, a V. está dançando. Vamos lá". [...] Quando eu vejo isso que perpassa a equipe, é isso, o oficineiro que é músico consegue falar de um caso, relatar o seu atendimento pela via da transferência, levando em consideração isso, pensando isso. (E2)

Segundo Kyrillos Neto \& Moreira (2009), a psicanálise assume um caráter político quando se fundamenta em uma posição subjetiva de responsabilidade em sua relação com o sujeito do inconsciente. Para os autores, a dimensão política do processo psicanalítico está ancorada na alteridade, a partir do reconhecimento do outro, e na transferência.

O termo "transferência" designa o processo pelo qual os desejos inconscientes se atualizam na relação com o terapeuta, tendo como modelo um tipo de relacionamento preestabelecido. "[...] por outrolado, as manifestaçôes transferenciais não são literalmente repetiçôes, mas equivalentes simbólicos do que é transferido" (LAPLANCHE, 2001, p. 520). Ou seja, a transferência diz da historicidade e da singularidade do sujeito e, como refere Silva (2016), a subjetividade se constitui na relação com a alteridade. Além disso, a partir da noção de campo transferencial, há de se ter claro que as atualizaçóes dos desejos inconscientes se inserem no conjunto da cultura e da sociedade do qual fazem parte (HERRMANN, 2010). O sujeito em psicanálise, por sua vez, é aquele que se distingue de um ser da consciência filosófica e daquele biológico, dando lugar 
ao sujeito desejante, partindo da noção do inconsciente (TOREZAN; AGUIAR, 2011). E esse sujeito é compreendido no laço social e, portanto, é concomitantemente individual e coletivo (KYRILLOS NETO, 2009).

As entrevistadas também enfatizam a importância da compreensão dos processos subjetivos e intersubjetivos para o entendimento, enquanto gestoras, do funcionamento da equipe e da instituição. Através dos aportes teóricos e técnicos advindos do campo psicanalítico, as gestoras adquirem ferramentas para compreender, suportar e interagir com os dramas intersubjetivos presentes na cena institucional, tal como propóe Onocko-Campos (2007). “[...] eu acho que é isso de poder escutar o outro, escutar uma equipe, o que que tem ali, para além do que está sendo dito". (E5)

[...] eu acho que tem uma coisa das relações que [...] a psicanalise é a que melhor explica, dessa coisa toda do inconsciente, a gente se comunica também pelos inconscientes e é a partir daí que essas relaçôes elas vão aparecendo [...] e saber ler isso, saber entender essas relaçóes, enfim, a partir dessa leitura é uma coisa que para mim tem auxiliado muito e faz sentido [...] e eu acho que me traz alguma perspectiva de tentar "lidar com" [...]. (E3)

Para Freud (1969), a vida em sociedade constitui-se como fonte de mal-estar e hostilidade. Conforme o autor, nem mesmo o avanço nas ciências naturais, através dos progressos científicos e técnicos, e o controle sobre a natureza foram capazes de aumentar a satisfação e a felicidade do ser humano. Para obter mais segurança através da vida em sociedade, o sujeito primitivo precisou abrir mão de uma parte de suas possibilidades de felicidade, por meio da restrição das pulsôes.

A partir da compreensão da função psíquica da cultura e da condição de mal-estar como componente inevitável da civilização ocidental, as instituiçôes caracterizam-se como espaços privilegiados para a sublimação e a vida social e cultural. Elas podem se estabelecer enquanto espaços de controle, alienação e dominação ou, por outro lado, como produtoras de autonomia, criatividade e desalienaçáo. No que tange à gestão, o reconhecimento dos processos inconscientes que circundam as instituiçôes pode capacitá-la como importante produtora de processos de subjetivação, através da propiciação de espaços que se estabeleçam como suporte à grupalidade, ajudando-a a estruturar-se como intersubjetividade (ONOCKO-CAMPOS, 2007).

As entrevistadas apontam, entretanto, para a necessidade de aproximação da Psicanálise com o campo da Saúde Mental, haja vista que essa, muitas vezes, se mantém encastelada, restrita aos moldes tradicionais. Desse modo, náo consegue 
produzir um discurso e um fazer extramuros, que levem em conta a condição sóciohistórica dos sujeitos (GUIRADO, 1992).

Eu acho que se a gente ficar numa psicanálise muito clássica, a gente não vai fazer isso dentro de um serviço de saúde mental, muito menos na gestáo [...] com os usuários [...] a transferência vai ser com o CAPS, não vai ser com aquele técnico específico. (E1)

[...] Então se tu tem uma política que tá centrada numa indústria farmacêutica, que entende que tudo se resolve por medicação ou que tudo é só em cima de um divã ou que é num consultório privado que tu vai resolver, tu vai estar sucateando o SUS. As pessoas não vão estar podendo acessar o SUS, vão estar cada vez gastando mais dinheiro, então quem tá lá no suposto conforto do seu consultório também é afetado por isso e, bom, o serviço público é para ser assim, o que a política pública determina é o que tem que estar acontecendo aqui dentro. (E6)

As entrevistadas também discorrem sobre as dificuldades de diálogo entre a Psicanálise e outros campos de saberes, em espaços de discussão, como reuniôes. Essas interposições à comunicação se colocam quando o discurso psicanalítico se torna incompreensível para seus interlocutores, fator que contribui para seu afastamento e enclausuramento.

[...] talvez em alguns momentos [...] o distanciamento... [...] quando a coisa começa a ficar muito psicanalítica, as pessoas se afastam [...] então é a velha coisa dos conceitos, de onde é que tu estás, que conceito tu usas, e ter essa noção de que tu só pode falar algo que possa ser compartilhado com todos, senão tu exclui, fica uma conversa dual ou trial. (E4)

[...] mas eu tenho essa visão um pouco da psicanálise muito teórica, muito densa e de encontros de psicanalistas onde... a impressáo que eu fico de alguns encontros, de serem conversas pra ninguém conseguir compartilhar e entender nada, assim, que fica... o quanto mais difícil o outro fala parece que mais interessante a pessoa é. Para seguirem se encontrando para náo se compartilhar coisas (risos). (E6)

Segundo Guirado (1992), com frequência, é no movimento de se legitimar que a Psicanálise cria uma rede de sustentação, porém, ao mesmo tempo, o seu isolamento. Este surge, de acordo com a autora, quando a Psicanálise se configura como uma propriedade abstrata daqueles que a compreendem, pois são reconhecedores de sua prática como reveladora do inconsciente. Nesse movimento, criam-se as relações de monopólio e poder.

No contexto dos serviços de saúde mental, os sujeitos do campo transferencial são sobredeterminados pelo conjunto dessa prática institucional. Sendo assim, alguns pontos considerados centrais dentro do arcabouço teórico-técnico da Psicanálise, tais como a transferência e o inconsciente, devem ser contextualizados e relativizados, 
quando da sua transposição enquanto teoria concernente ao sujeito psicológico para a interpretação de fatos sociais (GUIRADO, 1992).

Quando desconsidera o contexto no qual se insere, neste caso o da saúde mental no contexto do SUS, a Psicanálise pode contribuir para a efetivação de procedimentos não orientados pela lógica reformista. Isso ocorre, como já indicado, através de discursos psicanalíticos marcados por teorizaçôes e abstraçôes incompreensíveis para os seus interlocutores, em que a Psicanálise assume um papel presunçoso e distanciado dos demais campos de saberes. Também se dá por meio da eleição de modelos de compreensão dos sujeitos próprios da clínica tradicional, que não levam em conta o contexto institucional, sócio-histórico e cultural no qual estes estão inseridos. Nesse sentido, algumas entrevistadas discorrem sobre a importância de uma Psicanálise que dialogue com outros campos de saberes, sobretudo, neste caso, com o da Saúde Mental.

[...] mas tu tem que desejar estar ali. Sem tu te identificar com isso, sem tu acreditar nisso

[...]. Eu me vejo muito numa posição de militante pela saúde mental e quem não tem essa posiçẫo está ali batendo ponto e a coisa não se sustenta [...]. (E6)

[...] para a gestão [...] acho que ela me ajuda [...] a saber que não tem nada completo, [...] que a circulação do saber também por outras profissões te faz não te colocar nesse lugar. [...] a psicanálise é também multidisciplinar, ela foi construída dessa forma [...]. (E5)

Embora advindos de contextos sócio-históricos específicos, os campos da Psicanálise, da Saúde Coletiva e da Saúde Mental se entrecruzam ao possibilitar à pessoa em sofrimento psíquico grave seu reconhecimento enquanto sujeito singular. Sujeito que é constituído por processos inconscientes e, ao mesmo tempo, pelas relaçôes e pela cultura em que está inserido. No contexto da gestão, a compreensão desses processos pelos gestores pode auxiliar no suporte à condução dos casos, também quanto ao manejo dos aspectos relacionais e subjetivos que perpassam a equipe e a instituição como um todo. A gestão, por seu turno, pode contribuir com a Psicanálise a partir da proposição de interlocução entre os diversos saberes e práticas e por se caracterizar como espaço onde a gestão da vida humana constituiu-se a principal diretriz do trabalho (CAMPOS, 2005).

\section{Considerações finais}

Observa-se, a partir das entrevistas realizadas, que a qualificação pelo trabalho, através da residência em Saúde Coletiva, auxiliou no estabelecimento de uma 
gestâo norteada pelos preceitos do SUS de compartilhamento das decisôes e para a hegemonia de um modelo assistencial orientado pela lógica reformista. Sendo assim, aponta-se para a necessidade da oferta de espaços de formação e qualificação para os gestores que atuam nos serviços públicos de saúde mental, que possam contextualizar a gestão a partir da perspectiva da Reforma Psiquiátrica e do modelo de gestão compartilhada, preconizados pelo SUS. Além disso, sugerem-se, assim como balizado pela Política Nacional de Educação Permanente em Saúde (BRASIL, 2004), a formação e a capacitação de todos os trabalhadores, por meio da educação permanente, para que possam ser continuamente discutidos os processos de gestão e atenção que ancoram cada serviço.

Foi possível observar, ainda, a coexistência nos serviços de saúde mental das lógicas reformista e manicomial, apesar da hegemonia da primeira nos últimos anos no país, após a implementação dos serviços substitutivos de saúde mental. A coexistência das diferentes lógicas de cuidado dificulta o fazer na gestão, exigindo uma atuaçáo marcada por conflitos, disputas e movimentos de resistência que recoloquem a lógica reformista em primeiro plano. Nos últimos anos, esses conflitos têm se intensificado a partir de mudanças orientadas pela lógica manicomial que vêm ocorrendo nas políticas de saúde e de saúde mental.

As entrevistadas indicaram algumas possibilidades de contribuiçóes da Psicanálise ao campo da Saúde Mental, no contexto da gestão, além de alguns limites. A Psicanálise é um campo de saber hegemonicamente advindo de estudos e intervençôes com a subjetividade, através da clínica tradicional. Necessita então, no seu encontro com a Saúde Mental, compreender os processos institucionais, sociais e históricos que permeiam a atuação nesse campo. Para isso, torna-se imprescindível que as universidades, bem como as instituiçóes psicanalíticas tenham, em seu currículo ou programa de seminários, leituras que considerem o sujeito psicológico na sua relação com a cultura e com as políticas sociais. O que se propóe, contudo, não é uma simples adaptação da Psicanálise a esses contextos, mas sua inserção de um modo que possibilidade seu enriquecimento e legitimação, a partir das contribuiçôes de outros campos de saberes.

Este estudo, ao mesmo tempo em que investiga em profundidade as inter-relaçôes entre os campos da Saúde Coletiva, da Saúde Mental e da Psicanálise, a partir de entrevistas com profissionais gestores, não obteve essas percepçôes de profissionais não gestores, usuários e familiares. Sendo assim, sugerem-se novos estudos que 
possam contemplar esses outros atores, agentes cogestores no fazer cotidiano dos serviços de saúde mental. ${ }^{1}$

\section{Agradecimentos}

O presente trabalho foi realizado com apoio da Coordenação de Aperfeiçoamento de Pessoal de Nível Superior - Brasil (CAPES) - Código de Financiamento 001.

\section{Referências}

AMARANTE, P. D. C.; TORRE, E. H. G. A constituição de novas práticas no campo da Atenção Psicossocial: análise de dois projetos pioneiros na Reforma Psiquiátrica no Brasil. Saúde em Debate, v. 25, n. 58, p. 26-34, 2001.

BARROS, S.; SALLES, M. Gestão da atenção à saúde mental no Sistema Único de Saúde. Rev Esc Enferm USP, v. 45, n. spe2, p. 1780-1785, 2011.

BOYATZIS, R. E. Transforming Qualitative Information: Thematican Analysis and Code Development. Thousand Oaks: Sage, 1998.

BRASIL. Ministério da Saúde. Portaria $n^{\circ}$ 198/GM, de 13 de fevereiro de 2004. Política Nacional de Educação Permanente em Saúde como estratégia do Sistema Único de Saúde para a formação e o desenvolvimento de trabalhadores para o setor e dá outras providências. Disponível em: <https://www.nescon.medicina.ufmg.br/biblioteca/imagem/1832.pdf>. Acesso em: 31 out. 2019.

Portaria $n^{\circ}$ 2.436, de 21 de setembro de 2017. Disponível em: <http://bvsms.saude. gov.br/bvs/saudelegis/gm/2017/prt2436_22_09_2017.html>. Acesso em: 14 out. 2018a.

. Portaria $n^{\circ}$ 3.088, de 23 de dezembro de 2011. Disponível em: <http://bvsms.saude. gov.br/bvs/saudelegis/gm/2011/prt3088_23_12_2011_rep.html>. Acesso em: 10 out. 2019.

Programa permanente de capacitação de recursos humanos para a reforma psiquiátrica.

Brasília: Área Técnica de Saúde Mental, Secretaria de Assistência à Saúde, 2002.

Resolução $n^{\circ}$ 32, de 14 de dezembro de 2017. Estabelece as Diretrizes para o Fortalecimento da Rede de Atenção Psicossocial (RAPS), 2017b. Disponível em: <https://www. jusbrasil.com.br/diarios/173164140/dou-secao-1-22-12-2017-pg-239>

. Resolução no 510, de 07 de abril de 2016. Dispóe sobre as normas aplicáveis a pesquisas em Ciências Humanas e Sociais. Conselho Nacional de Saúde (MS). Brasília: Ministério da Saúde, 2016.

BRAUN, V.; CLARKE, V. Using Thematic Analysis in Psychology. Qualitative Research in Psychology, v. 3, n. 2, p. 77-101, 2006. 
CAMPOS, G. W. DE S. Humanização na saúde: um projeto em defesa da vida? Interface. Botucatu, v. 9, n. 17, p. 389-406, 2005.

. Saúde Pública e Saúde Coletiva: campo e núcleo de saberes e práticas. Ciênc. saúde coletiva, v. 5, n. 2, p. 219-230, 2000.

Um método para análise e cogestão de coletivos. $5^{\mathrm{a}}$ ed. São Paulo: Hucitec, 2015.

CASANOVA, I. A.; BATISTA, N. A.; RUIZ-MORENO, L. Formação para o trabalho em equipe na residência multiprofissional em saúde. Abcs Health Sciences, v. 40, n. 3, p. 229-233, 2015.

DOMINGOS, C. M.; NUNES, E. F. P. A.; CARVALHO, B. G. Potencialidades da Residência Multiprofissional em Saúde da Família: o olhar do trabalhador de saúde. Interface. Botucatu, v. 19, n. 55, p. 1221-1232, 2015.

FEUERWERKER, L. No olho do furacão: contribuição ao debate sobre a residência multiprofissional em saúde. Interface. Botucatu, v. 13, n. 28, p. 229-230, 2009.

FLICK, U. Introdução à pesquisa qualitativa. $3^{\mathrm{a}}$ ed. Porto Alegre: Artmed, 2009.

FREUD, S. O mal-estar na civilização. V. XXI. Rio de Janeiro: Imago, 1969.

GADELHA, A. K. DE S.; BARRETO, I. C. DE H. C. Residência integrada em Saúde: percepção dos atores da ênfase em Saúde da Família e Comunidade. Interface. Botucatu, v. 22, n. suppl 1, p. 1339-1351, 2018.

GUIRADO, M. Transferências e transferências. Psicol., Ciênc. Prof., v. 12, n. 2, p. 16-23, 1992. HERRMANN, F. Clínica Psicanalítica: a arte da interpretação. $3^{a}$ ed. São Paulo: Casa do Psicólogo, 2010.

KYRILLOS NETO, F. Reforma psiquiátrica e clínica da psicose: o enfoque da psicanálise. Aletheia, n. 30, p. 39-49, 2009.

KYRILlOS NETO, F.; MOREIRA, J. DE O. Política e psicanálise: conexóes. Psicol. clin., v. 21, n. 2, p. 397-414, 2009.

L'ABBATE, S. A análise institucional e a saúde coletiva. Ciênc. saúde coletiva, v. 8, n. 1, p. 265-274, 2003.

LAPLANCHE, J. Vocabulário de Psicanálise / Laplanche e Pontalis. $4^{\mathrm{a}}$ ed. São Paulo: Martins Fontes, 2001.

LEITE, L. DOS S.; SCARPARO, H. B. K.; OliveIRA, M. A. P. DE. A gestão da saúde mental em Porto Alegre: um breve recorte. In: SCARPARO, H. B. K.; BEDIN, D. M. (Org.). Gestão em saúde: experiências de campo e pesquisa com inserção social. Porto Alegre: Sulina, 2013. p. 129-140.

MAYORGA, C.; DINIZ, A.; MONTEIRO, D. B. L. Mapeamento dos CAPS em Minas Gerais. CliniCAPS, v. 3, n. 9, p. 1-49, 2009. 
MERHY, E. E. Saúde: a cartografia do trabalho vivo. São Paulo: Hucitec, 2002.

MINAYO, M. C. DE S. O desafio do conhecimento: pesquisa qualitativa em saúde. São Paulo: Hucitec, 2010.

MONTEIRO, A.; COIMBRA, C.; MENDONÇA FILHO, M. Estado democrático de direito e políticas públicas: estatal é necessariamente público? Psicologia \& Sociedade, v. 18, n. 2, p. 7-12, 2006.

MOROSINI, M. V. G. C.; FONSECA, A. F.; LIMA, L. D. DE. Política Nacional de Atenção Básica 2017: retrocessos e riscos para o Sistema Único de Saúde. Saúde em Debate, v. 42, n. 116, p. 11-24, 2018.

MUHR, T. ATLAS.ti. Versão 1.0.36 (129). Berlin: Scientific Software, 2013.

NORDI, A. B. DE A.; ACIOLE, G. G. Apoio matricial: uma experiência e a residência multiprofissional em saúde. Trab. Educ. Saúde, v. 15, n. 2, p. 485-500, 2017.

NUNES, E. F. P. A. et al. Trabalho gerencial em Unidades Básicas de Saúde de municípios de pequeno porte no Paraná, Brasil. Interface. Botucatu, v. 20, n. 58, p. 573-584, 2016.

NUNES, J. M. S.; GUIMARÃES, J. M. X.; SAMPAIO, J. J. C. A produção do cuidado em saúde mental: avanços e desafios à implantação do modelo de atenção psicossocial territorial. Physis: Revista de Saúde Coletiva. Rio de Janeiro, v. 26, n. 4, p. 1213-1232, 2016.

OHIRA, R. H. F.; CORDONI JUNIOR, L.; NUNES, E. F. P. A. Análise das práticas gerenciais na Atenção Primária à Saúde nos municípios de pequeno porte do norte do Paraná, Brasil. Ciênc. saúde coletiva. Rio de Janeiro, v. 19, n. 11, p. 4439-4448, 2014 b.

- Perfil dos gerentes de Atenção Primária à Saúde de municípios de pequeno porte do norte do Paraná, Brasil. Ciênc. saúde coletiva. Rio de Janeiro, v. 19, n. 2, p. 393-400, 2014a.

ONOCKO-CAMPOS, R. T. O encontro trabalhador-usuário na atenção à saúde: uma contribuição da narrativa psicanalítica ao tema do sujeito na saúde coletiva. Ciênc. saúde coletiva. Rio de Janeiro, v. 10, n. 3, p. 573-583, 2005.

ONOCKO-CAMPOS, R. T. A gestão espaço de intervenção, análise e especificidades técnicas. In: CAMPOS, G. W. DE S. (Org.). Saúde Paideia. São Paulo: Hucitec, 2007. p. 122-149.

ONOCKO-CAMPOS, R. T. Psicanálise e Saúde Coletiva: interfaces. São Paulo: Hucitec, 2012.

ONOCKO-CAMPOS, R. T.; FURTADO, J. P. Entre a saúde coletiva e a saúde mental: um instrumental metodológico para avaliação da rede de Centros de Atenção Psicossocial (CAPS) do Sistema Único de Saúde. Cad. Saúde Pública. Rio de Janeiro, v. 22, n. 5, p. 1053-1062, 2006. SILVA, T. C. R. DA; CAMPOS, M. M. Gestão de Saúde Mental em Município de Pequeno Porte no Estado do Rio de Janeiro. Vértices, v. 17, n. 315, p. 35-64, 2015. 
SILVA, M. D. O cuidado na saúde pública: potencialidades de uma clínica em movimento. ECOS, v. 6, n. 1, p. 64-76, 2016.

SULTI, A. D. C. et al. O discurso dos gestores da Estratégia Saúde da Família sobre a tomada de decisão na gestão em saúde: desafio para o Sistema Único de Saúde. Saúde em Debate, v. 39, n. 104, p. 172-182, 2015.

TEIXEIRA, C. F. O SUS e a vigilância em saúde. Rio de Janeiro: FIOCRUZ/ EPSJV/ PROFORMAR, 2004.

TENÓRIO, F. A reforma psiquiátrica brasileira, da década de 1980 aos dias atuais: história e conceitos. Hist. cienc. saude-Manguinhos. Rio de Janeiro, v. 9, n. 1, p. 25-59, 2002.

TOREZAN, Z. C. F.; AGUIAR, F. O Sujeito da Psicanálise: Particularidades na Contemporaneidade. Rev. Mal-Estar Subj., v. 11, n. 2, p. 525-554, 2011.

TURATO, E. R. Tratado da metodologia da pesquisa clínico-qualitativa: construção teóricoepistemológica, discussão comparada e aplicação nas áreas da saúde e humanas. Petrópolis: Vozes, 2003.

\section{Nota}

${ }^{1}$ R. M. Moreira participou de todas as etapas de elaboração do artigo, tendo sido responsável pela condução do estudo, resultante de dissertação de mestrado. K. B. Rocha supervisionou a pesquisa de mestrado, a concepção do estudo, redação e revisão do artigo. 


\section{Abstract}

\section{The work in the management of mental health substitutive services: between Collective Health, Mental Health and Psychoanalysis}

The objective is to investigate the interrelationships between the fields of Collective Health, Mental Health and Psychoanalysis in the management of mental health services in the context of the Unified Health System. This is a qualitative research carried out in four municipalities of the state of Rio Grande do Sul, Brazil, with six managers of mental health services identified with psychoanalysis. The instruments of data collection employed were a personal and sociodemographic data sheet and a semi-structured interview. Thematic analysis was used to analyze the data, resulting in the identification of three central themes: 1) Training and experience in management and in Collective Health; 2) Manicomial logic versus reformist logic: challenges to manage it; and 3) Psychoanalysis: between contributions and limits. The results point out the difficulties and the challenges to manage it in the face of the coexistence in the services of different logics of mental health care. Psychoanalysis is assumed as an ethical-political positioning based on the listening of the subjects' unconscious processes, which occur in the transferential field, contributing in the support to the understanding of the cases and in the management of relational and institutional aspects. On the other hand, there is a need to bring psychoanalysis closer to the context of mental health.

Keywords: psychiatric reform; psychoanalysis; health management; health manager; mental health services. 